\title{
KARAKTERISTIK KARBON AKTIF DARI PEMANFAATAN LIMBAH TANAMAN KELAPA SAWIT DENGAN PENAMBAHAN AKTIVATOR NATRIUM KARBONAT $\left(\mathrm{Na}_{2} \mathrm{CO}_{3}\right)$ DAN NATRIUM KLORIDA (NaCl)
}

\author{
CHARACTERISTICS OF ACTIVATED CARBON USING PALM OIL WASTE \\ PLANTS WITH ADDITION ACTIVATORS OF SODIUM CARBONATE ( $\left.\mathrm{Na}_{2} \mathrm{CO}_{3}\right)$ \\ AND SODIUM CHLORIDE ( $\mathrm{NaCl})$
}

\author{
Gewa Handika*, Seri Maulina, Vidyanova Anggun Mentari \\ Departemen Teknik Kimia, Fakultas Teknik, Universitas Sumatera Utara, \\ Jl. Almamater Kampus USU Medan 20155, Indonesia \\ *Email : gewadika@gmail.com
}

\begin{abstract}
Abstrak
Pohon kelapa sawit dapat menghasilkan 22 pelepah / tahun, rata-rata bobot pelepah per batang mencapai $2,2 \mathrm{~kg}$, sehingga setiap hektar dapat menghasilkan pelepah segar sekitar 9 ton / tahun atau setara dengan 1,64 ton/tahun bahan kering. Karbon aktif dapat digunakan sebagai agen penyerap yang baik untuk proses purifikasi gas dan penghilangan polutan organik dari air, seperti pada limbah cair. Paper ini bertujuan untuk mengetahui perbedaan karakteristik karbon aktif dari bahan baku pelepah kelapa sawit (elaeis guineensis Jacq) dengan variasi zat aktivator yaitu natrium karbonat $\left(\mathrm{Na}_{2} \mathrm{CO}_{3}\right)$ dan natrium klorida $(\mathrm{NaCl})$. Konsentrasi aktivator yang digunakan masing masing adalah $10 \%$ dengan suhu aktivasi $600^{\circ} \mathrm{C}$. Kualitas karbon aktif yang dihasilkan dilakukan analisis morfologi permukaan karbon aktif dan analisis spektra secara FTIR terhadap karbon aktif Hasil identifikasi dengan spektrofotometer FTIR menunjukkan bahwa karbon aktif pada penelitian ini mengandung gugus fungsi $\mathrm{O}-\mathrm{H}, \mathrm{C}=\mathrm{O}, \mathrm{C}=\mathrm{C}, \mathrm{C}-\mathrm{C}$, dan $\mathrm{C}-\mathrm{H}$.
\end{abstract}

Kata kunci : karbon aktif, pelepah kelapa sawit, natrium klorida, natrium karbonat.

\begin{abstract}
Oil palm tree can produce 22 oil palm frond / year, the average weight of frond per rod reaches 2.2 $\mathrm{kg}$, so that each hectare can produce fresh frond about 9 tons / year or equivalent to 1.64 tons / year of dry matter. Activated carbon can be used as a good absorbent agent for gas purification process and removal of organic pollutants from water, such as in liquid waste. The objective of this paper is to know the different characteristics of activated carbon from oil palm frond (elaeis guineensis jacq) as raw material with variation of activator sodium carbonate $\left(\mathrm{Na}_{2} \mathrm{CO}_{3}\right)$ and sodium chloride $(\mathrm{NaCl})$. The activator concentration used is $10 \%$ each with an activation temperature of $600^{\circ} \mathrm{C}$. The quality of activated carbons was analyzed by surface active carbon morphology and FTIR spectra analysis on activated carbon. The result of identification with FTIR spectrophotometer showed that the activated carbon in this study contained the functional groups of $O-H, C=O, C=C, C-C$, and $C-H$.
\end{abstract}

Keywords: activated carbon, oil palm froond, sodium chloride, sodium carbonate.

\section{Pendahuluan}

Kelapa sawit merupakan tumbuhan tropis yang telah dikenal selama dua dekade terakhir di negara-negara berkembang Asia Tenggara. Tanaman vegetatif ini memiliki peran utama pada berbagai proyek industri strategis, karena dapat meningkatkan pendapatan di berbagai sektor penting pada negara yang memproduksi kelapa sawit, seperti Indonesia, Malaysia, dan Thailand [1]. Setiap pohon kelapa sawit dapat menghasilkan 22 pelepah/tahun, rata-rata bobot pelepah per batang mencapai $2,2 \mathrm{~kg}$, sehingga setiap hektar dapat menghasilkan pelepah segar sekitar 9 ton/tahun atau setara dengan 1,64 ton/tahun bahan kering. Angka tersebut menunjukkan tingkat potensi yang besar dari pelepah sawit sebagai pakan temak, namun pemanfaatannya terkendala dengan rendahnya tingkat kecernaan karena kadar NDF (Neutral Detergent Fiber) dan Lignin yang tinggi [2] Pelepah kelapa sawit termasuk kategori limbah basah (wet by-products) karena masih mengandung kadar air sekitar 70-75\% [3,4], Jumlah produksi pelepah kelapa sawit sekitar 
$5500 \mathrm{~kg} /$ (ha)(tahun) [2]. Setara dengan 1,64 ton/tahun bahan kering. Angka tersebut menunjukkan tingkat potensi yang besar dari pelepah sawit sebagai pakan temak, namun pemanfaatannya terkendala dengan rendahnya tingkat kecernaan karena kadar NDF (Neutral Detergent Fiber) dan Lignin yang tinggi [4]. Ketersediaan tanaman kelapa sawit beserta limbahnya sangat besar dan melimpah. Limbah tanaman kelapa sawit dapat dikurangi dengan memanfaatkan limbah tanaman kelapa sawit sebagai bahan alternatif dalam pembuatan karbon, selain dapat meningkatkan manfaat dari limbah, diharapkan dapat memberikan nilai ekonomi yang lebih juga.

Berdarkan latar belakang diatas, maka perlu dilakukan penelitian tentang pembuatan dan karakterisasi karbon aktif dari pelepah kelapa sawit dengan aktivator natrium karbonat $\left(\mathrm{Na}_{2} \mathrm{CO}_{3}\right)$ dan natrium klorida $(\mathrm{NaCl})$.

\section{Teori}

Karbon aktif adalah karbon amorf yang luas permukaannya berkisar antara 300-3500 $\mathrm{m}^{2} / \mathrm{g}$ dan telah mendapat perlakuan dengan uap serta panas sampai mempunyai afinitas yang kuat sekali untuk menyerap (absorbsi) berbagai bahan dengan kemampuan yang besar yaitu 25-100\% terhadap berat karbon aktif [4]. Hal ini berhubungan dengan struktur pori internal yang menyebabkan karbon aktif mempunyai sifat sebagai adsorben. Karbon aktif dapat mengadsorpsi gas dan senyawa-senyawa kimia tertentu atau sifat adsorpsinya selektif, tergantung pada besar atau volume pori-pori dan luas permukaan.

Karbon aktif dapat digunakan dalam berbagai bidang seperti industri obat dan makanan untuk menyaring, penghilangan bau dan rasa. Industri kimia perminyakan, pembersih air, budi daya udang, industry gula, pemurnia gas, katalisator dan pengolahan pupuk [4].

Struktur permukaaan karbon aktif adalah berpori-pori. Bardasarkan IUPAC, ukuran pori diklasifikasikan menjadi daerah mikropori, daerah mesopori, dan daerah makropori [5]. Skema struktur pori karbon aktif dapat dilihat pada gambar 1 .

Proses pembuatan karbon aktif terdiri dari karbonisasi dan aktivasi. Aktivasi dalam pembuatan karbon aktif terdiri dari aktivasi fisika dan aktivasi kimia. Proses aktivasi yang umumnya pengaktivasiannya menggunakan gas aktivasi, gas yang biasanya digunakan adalah $\mathrm{N}_{2}$, $\mathrm{CO}_{2}$, dan uap air. Sedangkan, ciri khas aktivasi kimia adalah digunakannya suatu activating agent yang pada umumnya adalah golongan dari

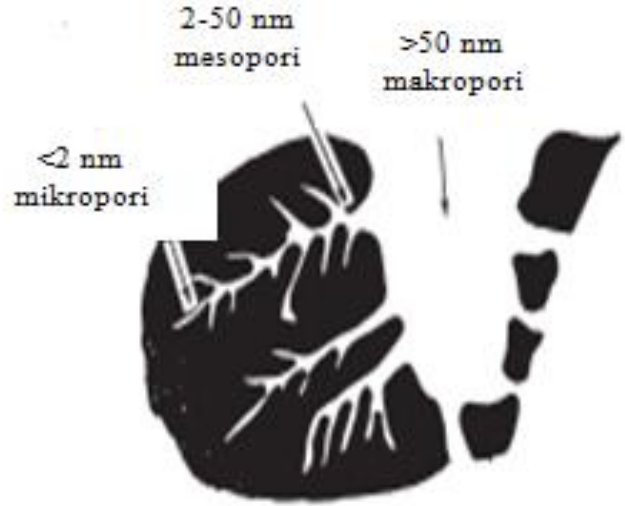

Gambar 1. Skema Struktur Pori Karbon Aktif

hidroksida $(\mathrm{KOH}$ atau $\mathrm{NaOH}), \mathrm{ZnCl}_{2}$, dan $\mathrm{H}_{3} \mathrm{PO}_{4}$.

Penelitian akan melakukan tentang studi perbandingan morfologi karbon aktif dari pelepah kelapa sawit dengan aktivator natrium karbonat $\left(\mathrm{Na}_{2} \mathrm{CO}_{3}\right)$ dan natrium klorida $(\mathrm{NaCl})$.

\section{Metodologi Penelitian}

Sebanyak 30 gram sampel dimasukkan ke dalam beaker glass untuk diaktivasi dengan 300 $\mathrm{ml}$ larutan natrium karbonat dan natrium klorida dengan konsentrasi $10 \%$ selama 2 jam pada suhu $80{ }^{\circ} \mathrm{C}$ dengan menggunakan hot plate. Kemudian diimpregnasi selama 24 jam pada suhu ruangan. Setelah sampel diimpregnasi, dilakukan penyaringan untuk memisahkan filtrat dan larutan. Kemudian filtrat yang dihasilkan di masukkan kedalam oven sampai kering.

\section{Hasil}

Analisis Morfologi Permukaan Karbon Aktif Struktur morfologi permukaan karbon aktif yang diperoleh dapat dianalisa dengan metode Scanning Electron Microscophys (SEM). Hasil analisa Scanning Electron Microscopy (SEM) pada karbon aktif yang dihasilkan dari pelepah kelapa sawit ditunjukkan pada Gambar 2

Pada Gambar 2 terlihat morfologi permukaan dari karbon aktif pelepah kelapa sawit memiliki permukaan pori-pori yang kasar dan tidak teratur. Hal ini disebabkan oleh proses aktivasi yang menghasilkan permukaan pori luar yang luas dengan permukaan yang tidak beraturan dan tersebar di seluruh karbon aktif. Proses aktivasi menyebabkan banyak senyawa volatil yang terlepas, sehingga membuka pori karbon dan mengurangi penutupan hidrokarbon. Hal ini sesuai yang dikemukakan oleh Novicio et.al. dan Bonelli et.al. (2001), pembentukan dan pembesaran pori disebabkan oleh penguapan komponen selulosa yang terdegradasi. 


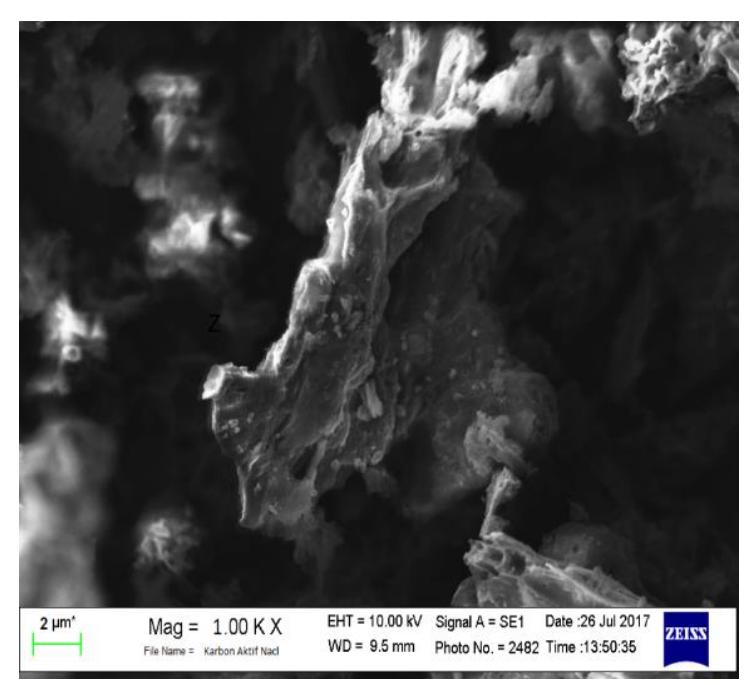

(a)

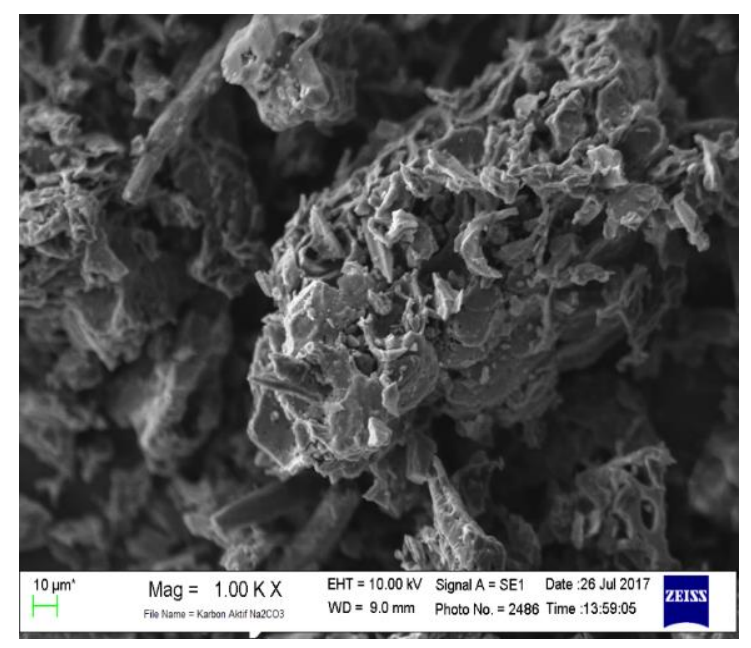

(b)

Gambar 2. Hasil Scanning Electron Microscophys (SEM) (a) Karbon Aktif dengan Aktivator Natrium Klorida (b) Karbon Aktif dengan Aktivator Natrium Karbonat

Pengurangan senyawa hidrokarbon menghasilkan permukaan karbon aktif terlihat semakin jelas. Proses aktifasi bertujuan untuk memperbesar pori yaitu dengan cara memecahkan ikatan hidrokarbon atau mengoksidasi molekul-molekul permukaan sehingga karbon mengalami perubahan yaitu luas permukaannya bertambah besar dan berpengaruh terhadap daya adsorpsi [6].

$\mathrm{Na}_{2} \mathrm{CO}_{3}$ terurai dari senyawa logam natrium menjadi karbon selama proses karbonisasi sesuai dengan reaksi berikut :

$\mathrm{Na}_{2} \mathrm{CO}_{3}+2 \mathrm{C} \longrightarrow 2 \mathrm{Na}+3 \mathrm{CO} \ldots$
Atom logam natrium yang terbentuk selama tahap aktivasi dan karbonisasi, dapat masuk ke dalam struktur karbon yang dapat memperluas pori-pori dan menciptakan porositas baru.

Pada Gambar 2a dan 2b terdapat perbedaan struktur pori karbon aktif teraktivasi $\mathrm{Na}_{2} \mathrm{CO}_{3}$ dengan karbon aktif teraktivasi $\mathrm{NaCl}$. Pada karbon aktif dengan aktivator $\mathrm{Na}_{2} \mathrm{CO}_{3}$, pori-pori yang terbentuk lebih banyak dan membentuk rongga-rongga pori dengan kedalaman yang lebih besar bila dibandingkan dengan karbon aktif teraktivasi $\mathrm{NaCl}$.

\section{Analisis Gugus Fungsi Karbon Aktif}

Analisa gugus fungsi karbon aktif yang diperoleh dapat dianalisa dengan metode Fourier Transform Infrared (FTIR), yaitu metode spektroskopi inframerah yang dilengkapi dengan transformasi Fourier untuk analisis hasil spektrumnya. Metode spektroskopi yang digunakan adalah metode absorpsi, yaitu metode spektroskopi yang didasarkan atas perbedaan penyerapan radiasi inframerah.

Gambar 3 adalah hasil analisa Fourier Transform Infrared (FTIR) pada karbon aktif yang dihasilkan.

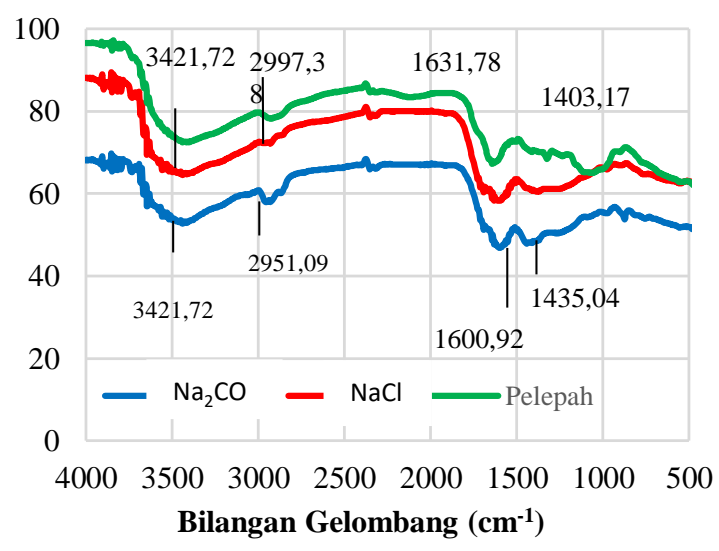

Gambar 3. Hasil Fourier Transform Infra Red (FTIR) pelepah kelapa sawit, karbon Aktif $\mathrm{Na}_{2} \mathrm{CO}_{3}$ dan karbon aktif $\mathrm{NaCl}$.

Puncak serapan $3421,72 \mathrm{~cm}^{-1}$ yang dimiliki oleh pelepah kelapa sawit, karbon aktif $\mathrm{NaCl}$. Puncak serapan pada bilangan 3500- 3200 $\mathrm{cm}^{-1}$ (merujuk pada O-H stretching) mengindikasi adanya gugus fungsi $\mathrm{O}-\mathrm{H}$ (hidroksil). Dari hasil yang diperoleh terjadi penurunan puncak serapan, hal ini karena penguraian gugus $\mathrm{OH}$ pada holoselulosa maupun lignin pelepah kelapa sawit. Peningkatan suhu saat karbonisasi menyebabkan gugus $\mathrm{OH}$ terurai membentuk struktur baru yaitu rantai karbon. Besarnya gugus hidroksil merupakan cerminan dari banyaknya senyawa kimia pada tempurung 
kemiri yang mengandung gugus $\mathrm{OH}$ seperti senyawa alkohol dan fenol [8]. Penurunan puncak serapan merupakan petunjuk mulai terbentuknya senyawa aromatik yang merupakan unsur penyusun karbon aktif [7].

Penggunaan aktivator kimia saat aktivasi ternyata masih berperan dalam mengidentifikasi gugus $\mathrm{O}-\mathrm{H}$ pada arang aktif. Gugus $\mathrm{O}-\mathrm{H}$ cenderung berasal dari reaksi antara zat aktivator dengan senyawa bebas pada permukaan karbon yang diaktivasi [9]. Gugus fungsi pada permukaan arang aktif yang diaktivasi dengan steam akan membentuk arang aktif yang bersifat polar.

Pada spektrum gelombang FTIR karbon aktif $\mathrm{NaCl}$, muncul puncak serapan dengan bilangan gelombang 1600,92 $\mathrm{cm}^{-1}$. Puncak serapan pada bilangan 1820-1600 $\mathrm{cm}^{-1}$ mengindikasikan keberadaan gugus $\mathrm{C}=\mathrm{O}$. Gugus $\mathrm{C}=\mathrm{O}$ merupakan gugus khas yang terdapat pada karbon aktif dan menunjukkan bahwa pelepah kelapa sawit membentuk zat aktif karbon [8].

Proses aktivasi pada karbon aktif $\mathrm{NaCl}$ juga telah membentuk ikatan $\mathrm{C}=\mathrm{C}$ yang ditandai dengan adanya pemunculan spektrum pada bilangan gelombang $1403,17 \mathrm{~cm}^{-1}$. Puncak serapan pada bilangan 1500-1400 $\mathrm{cm}^{-1}$ mengindikasikan keberadaan gugus $\mathrm{C}=\mathrm{C}$. Gugus $\mathrm{C}=\mathrm{C}$ menunjukkan adanya peningkatan kadar karbon.

Pada puncak serapan dengan bilangan gelombang 2951,09 $\mathrm{cm}^{-1}$ dan 2997,38 $\mathrm{cm}^{-1}$ mengindikasikan keberadaan gugus $\mathrm{C}-\mathrm{H}$ (3000$2850 \mathrm{~cm}^{-1}$ ) yang menunjukkan adanya senyawa alkana [9]. Gugus fungsi yang terdapat pada karbon aktif pelepah kelapa sawit yaitu gugus $\mathrm{C}=\mathrm{O}, \mathrm{C}=\mathrm{C}, \mathrm{C}-\mathrm{C}$ dan $\mathrm{C}-\mathrm{H}$.

\section{Kesimpulan}

Hasil penelitian yang dilakukan dan analisa mengenai morfologi dan gugus fungsi pada karbon aktif diperoleh pada morfologi permukaan karbon aktif teraktivasi natrium karbonat pori-pori yang terbentuk lebih banyak dan membentuk rongga-rongga pori dengan kedalaman yang lebih besar bila dibandingkan dengan karbon aktif teraktivasi natrium klorida.

Hasil identifikasi dengan spektrofotometer FTIR menunjukkan bahwa karbon aktif pada penelitian ini mengandung gugus fungsi $\mathrm{C}=\mathrm{O}, \mathrm{C}=\mathrm{C}, \mathrm{C}-\mathrm{C}$, dan $\mathrm{C}-\mathrm{H}$.

\section{Daftar pustaka}

[1] A. F. Ramdja, M. Halim dan J. Handi, Pembuatan Karbon Aktif dari Pelepah Kelapa (Cocus nucifera)", Jurusan Teknik Kimia, Fakultas Teknik, Universitas
Sriwijaya, Jurnal Teknik Kimia, No. 2, Vol. 15, April 2008.

[2] A. Imsya dan R. Palupi, Perubahan Kandungan Lignin, Neutral Detergent Fiber (NDF) dan Acid Detergent Fiber (ADF),Pelepah Sawit Melalui Proses Biodegumming sebagai Sumber Bahan Pakan Serat Ternak. Fakultas Pertanian Universitas Sriwijaya, Jurnal Nutrisi dan pakan, Vol. 3 No. 5, Maret 2009.

[3] A. Napitupulu, Impregnasi Karbon Aktif dengan Sulfida Untuk Mengikat Ion Tembaga (II) dan Kadmium (II) didalam Air. Program Studi Kimia, Sekolah Pascasarjana, Universitas Sumatera Utara, Jurnal Teknik Kimia Vol. 2, No. 3 (2009), ISSN : 2338-3357

[4] G. S. Pambayun, R.Y.E. Yulianto, M. Rachimoellah dan M.M. Putri, Pembuatan Karbon Aktif dari Arang Tempurung Kelapa dengan Aktivator $\mathrm{ZnCl}_{2}$ dan $\mathrm{Na}_{2} \mathrm{CO}_{3}$ sebagai Adsorben untuk Mengurangi Kadar Fenol dalam Air Limbah", Jurnal Teknik POMITS Vol. 2, No. 1, (2013) ISSN: 2337-3539.

[5] J. Mohammed., N. S.Nasri, M. A. A Zaini, U. D. Hamza, H. M. Zain dan F. A. Arif, Optimization Of Microwave Irradiated - Coconut Shell Activated Carbon Using Response Surface Methodology For Adsorption Of Benzene And Toluene", Journal of Desalination and Water Treatment. Vol. 4(2) No. 3

[6] M. J. A. Menéndez, A. A. B. Fidalgo, Y. Fernández, L. Zubizarreta, E.G. Calvo, J.M. Bermúdez, Microwave heating processes involving carbon materials", Journal Fuel Processing Technology, Vol 91 (2010) : 1-8

[7] O. Rodenas, M. A. Cazorla, D, SolanoLinares, Understanding Chemical Reaction Between Carbon and $\mathrm{NaOH}$ and $\mathrm{KOH}$ An Insight into the Chemical Activation Mechanism Carbon, Vol 41: 267- 275.

[8] S. C. Matthew, A. Adebayo, E. C. Lima, R. C. P. S. Thue, D. T. Prola, M.. J. Rosero, Microwave-Assisted Activated Carbon From Cocoa Shell as Adsorbent For Removal of Sodium Diclofenac and Nimesulide From Aqueous Effluents", Journal of Hazardous Materials Vol 289 (2015): 18-27

[9] S. Mansooreh and T. Kaghazchi, LowCost Adsorbents from Agricultural ByProducts Impregnated with Phosphoric Acid", Journal of Advanced Chemical Engineering Research. Vol : 3(1) 